\title{
XLV. An analysis of fluor-spar
}

\section{Thomas Thomson M.D. F.R.S.E.}

To cite this article: Thomas Thomson M.D. F.R.S.E. (1811) XLV. An analysis of fluor-spar , Philosophical Magazine Series 1, 37:156, 258-260, DOI: 10.1080/14786441108563280

To link to this article: http://dx.doi.org/10.1080/14786441108563280

$$
\text { 曲 Published online: } 18 \text { May } 2009 .
$$

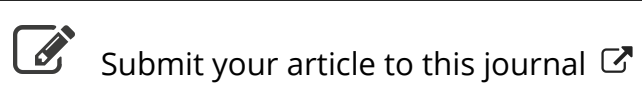

\footnotetext{
Џll Article views: 2
}

Q View related articles $\sqsubset$ 
the charge of the jar. The battery represents muriatic acid, the positive jar represents sulphuric acid, and the negative jar represents soda. The powers are reversed; but it does not affect the conclusion. These experiments may be made also by employing large and small conductors.

\section{Conclusion.}

If I have been thus free in stating my objections to the opinions of one of the most distinguished philosophers of the are, I was encouraged to proceed, when 1 reflected that, as the establishment of truth was the object of research, the discovery of error as a preparation, would be to no one more highly pleasing, than to the illustrious framer of this ingenious hypothesis.

XLV. An Analysis of Fluor-Spar. By Tномаs ТномSON, M.D. F.R.S.E.*

The mineral called Fluor-Spar has been long known, and valued on account of its beauty and the ease with which it can be turned on the lathe into various ornaments and useful utensils. It occurs chiefly in veins, and very frequently accompanies lead-ore. Some of its properties have been described more than a century ago; as, for example, its phosphorescing when heated, and its corroding glass when mixed with sulphuric or nitric acid. But it is not forty years since its composition was discovered by Scheele, who demonstrated that it is composed of lime and a peculiar acid called fluoric. Chemists now distinguish it by the name of fluate of lime.

Hitherto, no chemical analysis of this salt bas been published, except a very incorrect one by Kirwan and Gren, which has been ascribed to Scheele, though I cannot find it in any of his dissertations on fluor-spar. By that analysis, it is made to contain 27 per cent. of water,-a proportion very inconsistent with the properties of native fluate of lime, which, when strongly heated in a wind furnace, loses at an average only $\frac{1}{6} \mathrm{dth}$ part of its weight. The obvious inaccuracy of the analysis given by the authors just mentioned induced me to make a set of experiments on it last summer (1807). I selected the purest transparent colourless crystal, which I found by repeated trials to be very nearly pure fluate of lime. When reduced to a fine powder,

- From the Wernerian Transactions. 
and digested in nitric acid, 1 found in the acid only a little lime, owing doubtless to the partial decomposition of the fluate, and minute traces of iron and lead: these two metals I detected by evaporating the nitric solution to dryness, heating it to redness, and then dissolving the residue in muriatic acid. The colour of the solution showed the presence of iron, and a few needle-form crystals of muriate of lead were deposited after the solution had stood for some days. The fluate which $I$ used had been dug out of a lead-mine in Northumberland, and small crystals of sulphuret of lead were here and there to be seen in it. Probably some one of these had escaped my attention, and, by being mixed with the fluate which I used, occasioned the appearance of the lead, which, however, did not amount to $\frac{1}{30} \mathrm{dth}$ part of the salt, and therefore could not occasion any sensible error in the subsequent analysis.

I first tried to decompose the fluate of lime, by fusing it with twice its weight of carbonate of potash in a platinum crucible. Only a small portion of the fluate was decomposed. I was therefore obliged to repeat the fusions very often, washing off the alkali after each operation, by means of water, and then dissolving the carbonate of lime formed, in muriatic acid. Fatigued with the tediousness of this method, and despairing of an accurate result from the great number of successive solutions, I abandoned it altogether, and adopted the following inethod, much more expeditious and equally precise.

From a mass of fluor-spar which I had ascertained to contain no sensible portion of foreign matter, I separated 100 grains, which I reduced to powder, and digested for some hours in a platinum crucible, with rather mere than an ounce of pure concentrated sulphuric acid. The mixture was then evaporated to dryness, and the crucible exposed for an hour to a strong heat, in a wind-furnace. To ensure the complete decomposition of the fluor, the mass was reduced to powder, and treated a second time in the same manner with another ounce of sulphuric acid. The residue, which was white with a slight shade of red, proved on examination to be pure sulphate of lime. It weighed $156 \cdot 6$ grains.

Now it has been ascertained by the most careful experiments, that sulphate of lime thus violently heated contains 43 per cent. of lime. Of consequence, the whole quantity of lime in 156.6 grains of sulphate is 67.34 grains. This is obviously the whole lime contained in 100 grains of fluor spar; and since that mineral contains no sensible $\mathrm{R} 2$ portion 
portion of water, the remainder of the 100 must be fluoric acid. Hence fluate of lime is composed of,

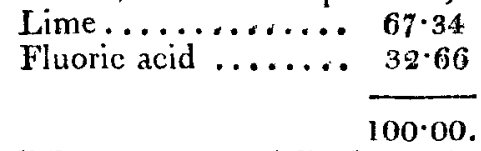

This result differs very materially from the analysis alluded to in the beginning of this paper, which makes the amount of the acid in the same weight of spar only 16 grains, and the lime 57 grains; the remaining 27 grains being considered as water. But, from the care with which my experiment was conducted, I flatter myself that the result which it extibits is very near the truth*.

XLVI. On the Gaseous Combinations of Hydrogen and Carbon. By Thomas Thomson, M.D. F.R.S.E. $\uparrow$

$T$

$\Gamma_{H E}$ gases formerly distinguished by the name of heavy inflammulle airs, which are evolved during the distillation of most animal and vegetable substances, differ so much from each other in their properties, that it has been hitherto impossible to reduce them under a small number of species. When burnt, they all yield carbonic acid and water, and of course contain carbon and hydrogen; but the proportion of these bodies formed, and of oxygen consumed, during the combustion, varies very much at different times. Many of these gases have been examined with much address by Cruickshanks, Dalton, and Henry. Berthollet also has examined them at different times, and published very ingenious dissertations on their composition.

From a great many experiments on these gases, at different times, and in different states, I have convinced myself that they ustally bold an empyreumatic oil in solution, and that the differences in their specific gravity, and other properties, depend very much upon the proportion of oil present. Hence no pure gases, fit for examination, and comparable with each other, can be obtained from those vegctable or animal substances which yield an oil when subjected to heat, as is the case with most of them. To this oil is to be ascribed the great variation in the specific

* Since the preceding paper was read, I have seen an analysis of fluorspar by Klaproth, in the thh volume of his Beiträge, conducted in a very different mamer from mine, but leading to almost the very same result. He found fluate of lime composed of $67 \frac{3}{4}$ lime, and $32 \frac{3}{4}$ acid,-gitantities which eoincide with mine within less than 1 per cent.-Nov. 1809 .

t From the Wernerian Transactions. 